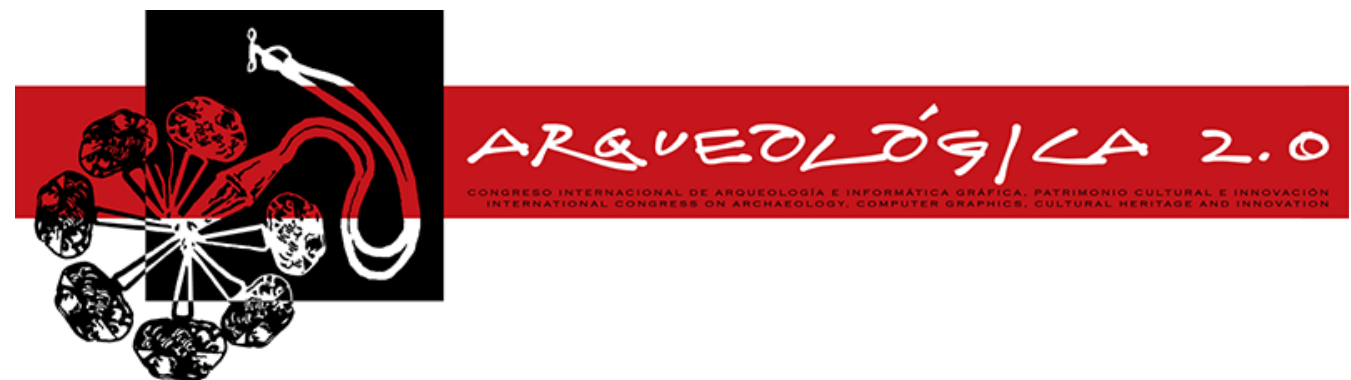

Proceedings of the $8^{\text {th }}$ International Congress

on Archaeology,

Computer Graphics,

Cultural Heritage and Innovation

'ARQUEOLÓGICA 2.0'

in Valencia (Spain),

Sept. 5-7, 2016

DOI: http://dx.doi.org/10.4995/arqueologica8.2016.3550

Received: 01/03/2016

Accepted: 25/05/2016

\title{
SELF-EXPLAINING VIDEOS FOR THE MUSEO EGIZIO IN TURIN
}

\author{
VIDEOS AUTOEXPLICATIVOS PARA EL MUSEO EGIPCIO DE TURÍN

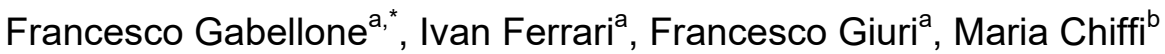 \\ ${ }^{a}$ CNR - IBAM (Istituto per i Beni Archeologici e Monumentali), Via prov.le Monteroni, 73100 Lecce, Italy. f.gabellone@ibam.cnr.it; \\ itlab.ferrari@ibam.cnr.it; itlab.giuri@ibam.cnr.it \\ ${ }^{\text {b } A r k e m a t i c a ~ s . r . I ., ~ C o n t r a d a ~ S o v a r e t t e ~ S o t t a n e, ~ 40 / 41, ~} 87040$ Cosenza, Italy. maria.chiffi@libero.it
}

\begin{abstract}
:
In the present project for the setting of the new Museo Egizio of Turin the "cultural message" has been charged to make a few specific 3D computer graphic (CG) movies, and aims to introduce the topics dealt with the rooms dedicated to queen Nefertari, the chapel of the painter Maia and the tomb of Kha, respectively. In these movies, the passivity of viewing is counteracted with an emotional approach that involves the visitor within an informative path where, despite of the inactive kind of interaction, the viewer is somehow involved in the events because he or she is emotionally invested in them. Thanks to this passive and "self-explaining" approach, the visitor will be enabled to understand the relations between different objects, some of which are not directly visible. Moreover, the visitor will be able to virtually insert the tombs within their original context and above all will have the possibility to visit them as they appeared at the moment of their discovery. This has been made possible thanks the use of integrated technologies of representation, able to enhance the virtualization process to a verisimilar level allowing a hyper-realistic and "participative" vision. The high level of realism of the virtual reconstruction, the visual effects and the cinematographic representation, with added emotions to the scientific contents, positively contribute to the "dreamlike displacement" of the visitor between the real and the virtual dimensions.
\end{abstract}

Key words: virtual archaeology, digital archaeology, Museo Egizio, 3D reconstruction, 3D image based

\section{Resumen:}

En este proyecto para la construcción del nuevo Museo Egipcio de Turín el mensaje cultural fue dado a tres películas específicas en gráficos 3D, destinados a la introducción de los temas tratados en las salas dedicadas a la reina Nefertari, la capilla del pintor Maia y la tumba de Kha. En estas películas, la pasividad de la visión se ve compensado por un enfoque emocional que implica el visitante en un trayecto de información en el que, a pesar de la falta de actividad de disfrute, él es en realidad participante, porque emocionalmente involucrado. Gracias a este método, pasivo y "autoexplicativa" el visitante puede comprender las relaciones entre diferentes objetos, algunos no directamente visibles, como la momia de Kha y su esposa Merit, a ser posible reconstruir las tumbas en su contexto original, pero sobre todo la posibilidad de visitar, gracias a las técnicas de la arqueología virtuales, tales contextos como aparecieron en el momento de su descubrimiento. Todo esto es posible gracias a la utilización de tecnologías integradas para el estudio y la representación, capaz de llevar el proceso de virtualización a un grado de verosimilitud hiperrealista y "participativa". El alto grado de realismo de las reconstrucciones virtuales, efectos visuales y técnicas de representación cinematográfica, añadiendo emoción al contenido científico, contribuyen positivamente a la "pérdida" del visitante entre el real y el tamaño dimensión virtual.

Palabras clave: arqueología virtual, arqueología digital, Museo Egizio, reconstrucción 3D, 3D image based

\section{Overview about active and passive presentation}

Multi-modal information and dynamic narratives have really changed the exhibition methods in modern museums and, at the same time, enable an efficient reading of cultural contents by the public. The impulse of new technologies has powerfully imposed new forms of communication, based above all on digital content. From recent studies it is clear that all the museums that have characterized their cultural offerings through digital technologies and the active participation of the public have achieved the greatest success in terms of number

*Corresponding Author: Francesco Gabellone, f.gabellone@ibam.cnr.it 
of visitors and, probably, a greater understanding of cultural information by the public. In this context, our proposal of communication for the Egyptian Museum of Turin which uses three-dimensional technologies for survey, reconstruction and computer animation, is useful in order to accelerate and enhance the cognitive capabilities of the visitor. It has the perspective to offer a medium capable of efficiently generating "virtuous processes" of learning.

Our idea is to evoke the ideas of the past and to inform the visitors through a modern approach that is efficient but above all philologically correct. The message that is developed to be communicated through the use of technologies of three-dimensional representation becomes an important component of the process of musealization, by way of imagining the cultural communication that puts new museums in the wake of the current dynamics of social communication. In this specific case we have not adopted communication solutions based on interactivity or immersivity, which would require the active participation of the visitor, as requested by the most common modern technological scenarios.

This choice was motivated by the need to avoid prolonged stops of the visitors within some thematic rooms, but also because the concerned spaces, due to the organization and distribution of exhibits, were not set up to accommodate large groups of people forming queues. So, the main rules to be followed were two: to produce easily understood content that could be seen quickly. Another important element is related to the ability to manage informatical tools. In effect, all active systems require from the public a certain expertise and this, no matter its perceived simplicity, is not always easy to find in certain age groups, or even more problematic, in visitors with cultural backgrounds that are reluctant to use interactive solutions. The last consideration regards the number of visitors that, at the same time, view digital content. Although it is true that in recent times multi-user applications are considered a rapidly growing sector, it is generally true that an interactive system can be managed by only one person at a time, or at best by two or three people simultaneously. All this is only possible with complex systems, which in our recent experience of other museum installations, have shown a certain weakness in garnering intensive use, requiring continuous interventions of software and hardware settings.

While not informed about these our reflections concerning our experience about the usability of active systems, the museum management has deemed it appropriate to entrust the entire communication process to passive animated narratives, orsimple movies. These introduce the basic themes of the topics dealt in the rooms and lead the visitor on a fascinating journey that evokes spaces, objects and historic The tomb of Kha ures involved in the discoveries. All in according with scenographic settings, narrative paths and informational approaches designed to produce an effective transmission of a cultural message, without any hint to forms of dramatization that do not produce new information, compared to pure vision of real objects exposed in the rooms.

\section{The reconstruction of the discovery}

Three specific movies based on 3D computer graphics were created for the transmission of cultural content, designed to introduce the topics covered in the rooms dedicated to Queen Nefertari, the chapel of the painter Maia and the Tomb of Kha. These are archaeological contexts of extraordinary importance for the study and knowledge of the art and culture of ancient Egypt, all of which were discovered by the Italian Egyptologist Ernesto Schiaparelli in the early years of the twentieth century. In the production of the film the presentation of narrated comments was deliberately omitted, choosing to present only bilingual textual infographics (Italian / English). Such textual information was reduced to a minimum, assuming the role of quick captions that strengthen the main message assigned to the images in sequence. In fact, the reading over the display of the text, done in accordance to this simple scheme, shifts the focus of the narrative and on the communicative power of computer graphics animations. In this way it can represent the reconstructed scenarios using unusual patterns, in animated section, in orthogonal view or with shots impossible in the real world. We found great utility in the original photographic documentation, a rare example of a modern approach to archaeological excavation itself. Many photos were made in stereoscopic mode, a well-known technique at the time of the discovery, which represent an important tool to document even in the third dimension and are also useful for the survey purposes.

\section{The emotional approach}

Through means of expression offered by computer animation one can re-read and re-create the single identity of "place", generated by time and by human activity, to present it again in forms of communication which can bring a high degree of knowledge with multidisciplinary content. It is undeniable the role and impact of the emotional narrative every time they treat themes related to the re-evocation of the ancient, with its forms, its awesomeness, its colours and the lost atmosphere that we are called to represent. Only through accurate scientific reconstructions (Figs. 1, 2 and 3) can we create engaging stories guiding the visitor in an information path in which, despite the lack of enjoyment, can feel in part emotionally involved. A high degree of realism in virtual reconstructions, visual effects and techniques of cinematic representation, adds emotional content to the scientific content, contributing positively to the "loss" of the visitor's differentiation between the real dimension and the virtual dimension. In this sense, it may be acceptable to note the philosophical position of Heidegger on the concept of the presence of the "Being" - Dasein - that does not indicate a mere spatial location, but something more ambiguous and complex, or the way in which the Being concretely (in a phenomenological way) is "present" in a history, as part of humanity. Developing this "sense of presence" and emotional involvement, is a well known purpose of three-dimensional representation as part of an internal and essential language of Virtual Reality: developing a dematerialization of the object, but with the need to make it "comprehensible", present, and almost real. 


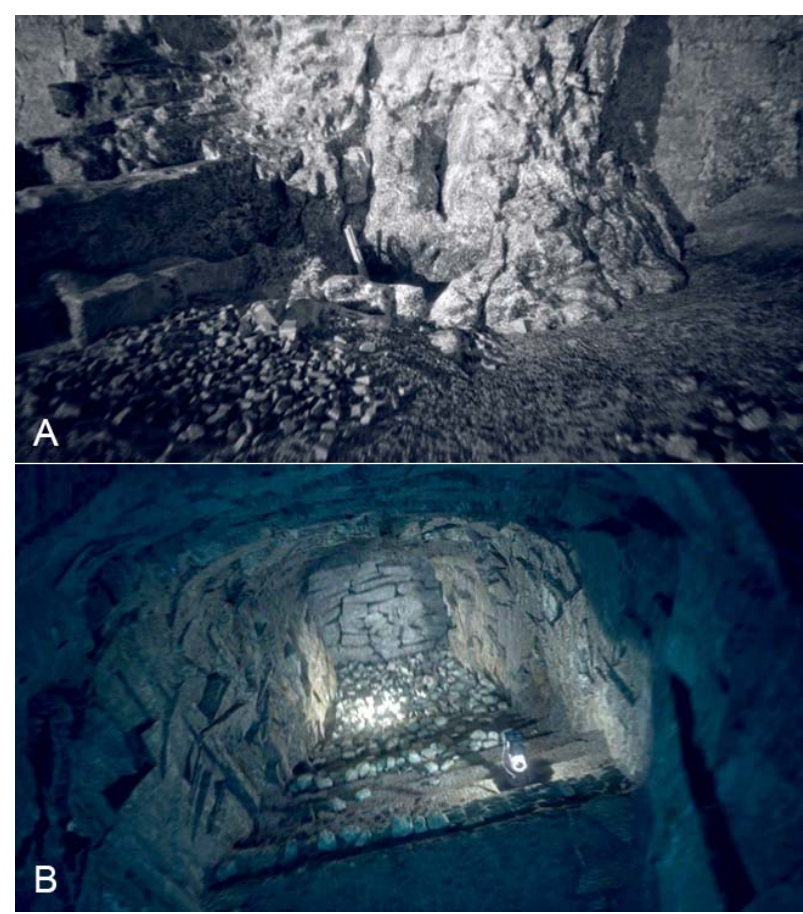

Figure 1: Reconstruction of the tomb of Kha: the entrance pit (A) the entrance corridor (B).

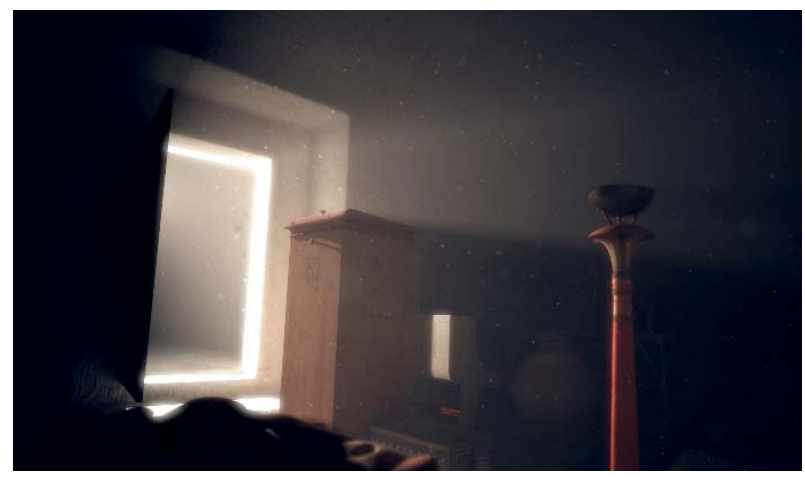

Figure 2: Tomb of Kha, reconstruction of the discovery.

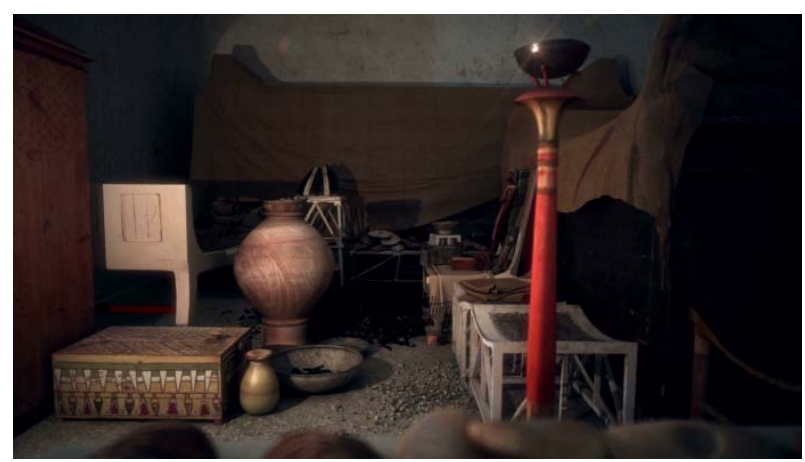

Figure 3: Reconstruction of Tomb of Kha, using 3D ImageBased and NURBS models.

\section{Techniques and methods for 3D reconstruction}

All of these reasons form the basis for continuous research into the best rendering quality in conjunction with philological approaches. Using the most recent achievements in 3D image-based survey, we restitute in three dimensions almost one hundred objects of the tomb of Kha, then virtually recollected them in their original context to become the basic elements of a narrative. Thanks to the passive "self-explaining" approach described above, the visitor will understand the relationships between different objects, some not directly visible in the museum room, such as the mummy of Kha and his wife, Merit. Ideally, the visitor can rebuild the finds in their original context, but especially moreimportantly be able to visit these contexts as they appeared at the time of their discovery, thanks to the techniques of virtual archaeology.

As the entire project was completed in just three months, we used only rapid survey technologies in an effort to keep the metrical data under control, considering that the final goal is not the survey itself, but the representation and the contextualization of all finds. From an operative and technical point of view we used two different technologies: the objects characterized by a rather simple geometry were modelled with NURBS techniques using frontal photos that were orthorectified with the help of direct measurements (Fig. 4). More complex objects, such as sarcophagi, statues and the mask of Merit, were recognized using Agisoft PhotoScan, a well known program that uses algorithms such as SfM (Structure from Motion) for the generation of 3D models complete with textures (Fig. 5). Diverging from normal operational practice, after the generation of the mesh, every model was temporarily exported (in obj format) into software for 3D sculpting in order to manually manage some small anomalies over the surface and to apply a smoothing algorithm to eliminate the $3 \mathrm{D}$ noise caused by high ISO and by the uncertainty of some measurements, due to the poor lighting and the low surface characterization of some parts. The acquisition of 3D models in environments with low light is a significant problem, especially when it is impossible, as it was in this case, to set up a professional still-life with additional lights to reduce the high ISO. Later, the models were re-imported into PhotoScan (in the same obj format) for the definitive computing of the textures, typically with a resolution of $10000 \times 10000$ pixels.

The virtualization of the tomb allows us to understand the exact position and morphology of the burial assemblage, as well as that which was discovered and documented in detail through the excavation journals and photographs of E. Schiaparelli. (Figs. 6 and 7). As said previously, this instrument was used by the Italian as a real form of documentation of excavation and thanks to these old photos it was possible to reconstruct the entire discovery, from the opening of the entrance pit until the opening of burial chamber. His images have been reused in these movies and reprocessed with matte painting and camera mapping techniques in order to offer the visitor the exact feeling of the discovery. The metrically accurate $3 \mathrm{D}$ scenes have been used to superimpose archival images with a colour representation of the tomb, where the individual objects viewable in the museum return to life in the background. The vision of the movie prepares the visitor to visit the museum rooms, but it is also a moment of study and reading of the whole information of context, reconnected to the votive chapel and to the site of Deir-el-Medina. The tomb of Kha was represented with different techniques and methods, including sections in perspective view and continuous camera movements 
giving direct information in a simple way without mediation or excessive fragmentation of the communicated message. The narrative proceeds without emphases given by special effects, but just provide information and points of view that allow for understanding everything in a dynamic and sequential way, with a scale that begins from the village of Deir-elMedina and continues down to the smallest objects.

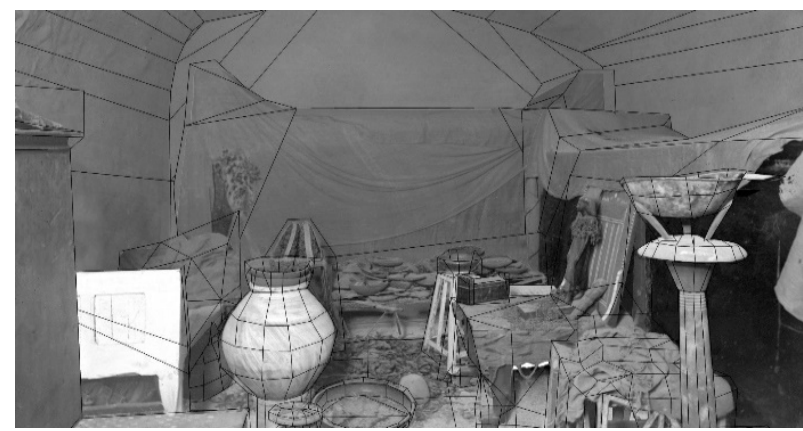

Figure 4: Camera Mapping of old real photo.

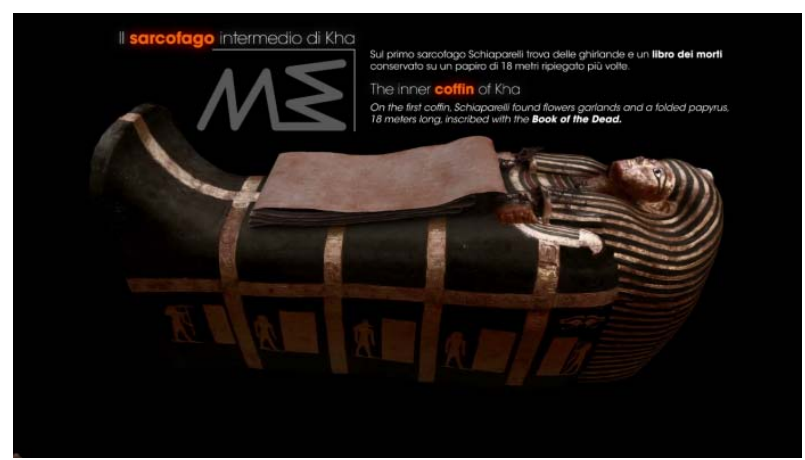

Figure 5: 3D model of inner coffin of Kha, obtained with IB techniques.

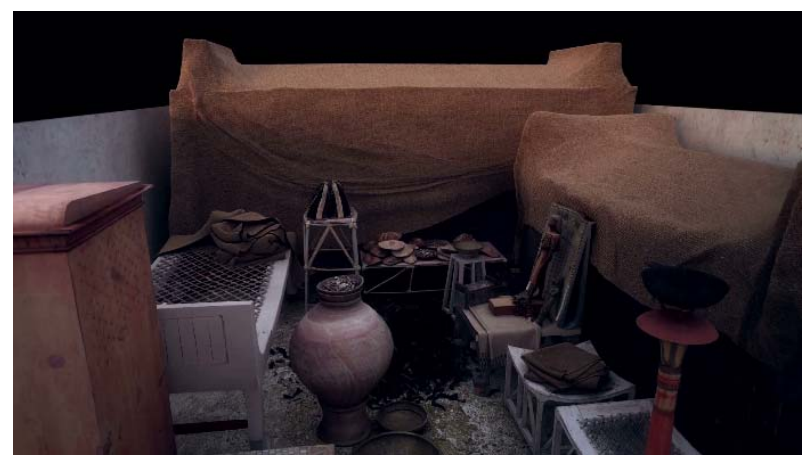

Figure 6: Tomb of Kha, screenshot of the reconstructed interiors.

The second film regards the chapel of Maia, the already mentioned painter that worked in the necropolis of Deirel-Medina. His frescoes that were "detached" from the original walls are currently exhibited in the museum. In this setting, a virtual reconstruction of the small building with the fragments of paintings appropriately integrated with outline drawings has been proposed. All this would be done in order to clarify the complex reading of all registers (Fig. 8).

Even here, the historical images properly reconstructed in $3 \mathrm{D}$ using the techniques described above serve as support for the description of the funerary ritual represented in the paintings. The overall view describes the contents of the registers in the order of reading and allows one to observe the ritual procession horizontally, in accordance with its natural development. Increased zoom over the figures allows one to appreciate the features and stylistic details, with additions of reconstructive drawings that complete, as far as possible, the description of the ritual.

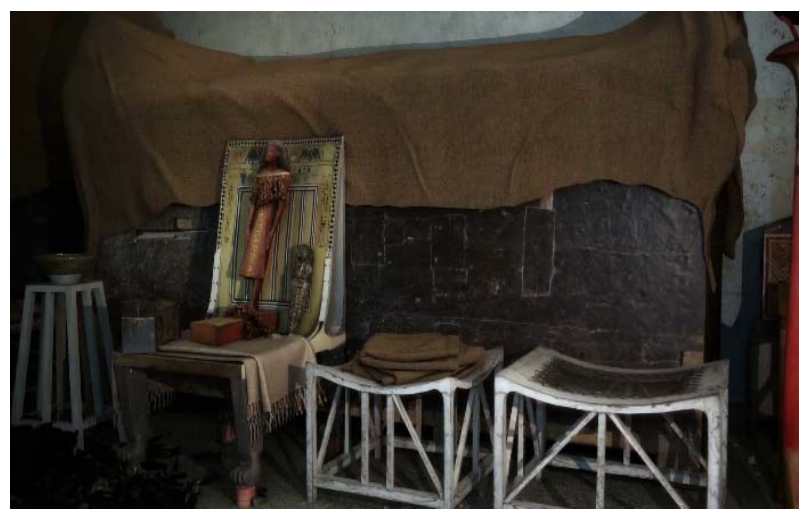

Figure 7: Tomb of Kha, screenshots of the reconstructed interiors.

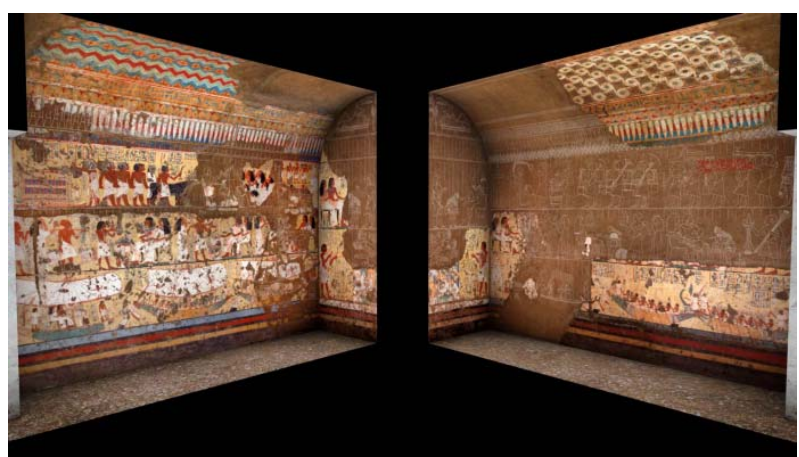

Figure 8: Reconstruction of Chapel of Maia.

Even here, the historical images properly reconstructed in 3D using the techniques described above serve as support for the description of the funerary ritual represented in the paintings. The overall view describes the contents of the registers in the order of reading and allows one to observe the ritual procession horizontally, in accordance with its natural development. Increased zoom over the figures allows one to appreciate the features and stylistic details, with additions of reconstructive drawings that complete, as far as possible, the description of the ritual.

The third film concerns the cycle of paintings that decorates the hypogean tomb of Nefertari, one of the most complete and important of the New Kingdom. This vast tomb discovered in 1904 by the Egyptologist Ernesto Schiaparelli, unfortunately looted and deprived of the mummy, is located on the northern slope of the Valley of the Queens and has a highly articulated plan. It is in fact different from the tombs of other queens (usually more simple, with only one burial chamber) and was rather inspired by the pharaonic tombs of the nearby Valley of the Kings. The paintings reach the acme of quality in Egyptian funerary art especially for their richness in colours (green, Egyptian blue, red, yellow ocher, white and black) and detail, while the themes and content respect the information supplied in 
the Book of the Dead. The images describe the journey to the afterlife of Nefertari, during which she plays the Senet, and enters the underground world where she encounters many gods such as Osiris and Isis.

At the end of the cycle of paintings, Nefertari triumphs and turns into Osiris (god of the dead), with the consequent, advocated reaching of immortality and eternal peace. The museum keeps the sarcophagus of Queen Nefertari and a wooden maquette of the entire royal tomb accompanied by pictorial decorations, meticulously replicated when discovered. A document of considerable interest for a complete view of a cycle is now no longer legible in its entierety. The context was restituted in 3D (Fig. 9) in order to illustrate the path of solarisation and deification of the Queen after death, which involve the visitor in a virtual and emotional journey within the underworld, among the Egyptian gods, having as a point of connection just the real objects exposed in the museum room.

This process of historical re-evocation is developed in accordance with a cinematographic approach, which integrates the techniques of synoptic representation of the paints used for the chapel of Maia and combines the animation of 3D wooden model displayed in the museum. The narratives allow us to understand the figurative themes and the dynamic development of the path of deification and the spatiality of the tomb, one of the most beautiful of the Valley of the Queens.

\section{Conclusions}

The virtualization of the three contexts described in this paper allows visitors to the Museo Egizio in Turin to better recognise the characteristics of the objects exposed in the rooms, but at the same time enable the visitor to contextualize and understand the relationships between them. Many objects not directly visible in the rooms are described adequately in the video e.g. the organization of three coffins of Kha and the correct view of smaller finds originally contained in the boxes. Image- based technologies and NURBS modeling based on orthophotos made it possible to restitute nearly 100 funerary objects, which were used to complete the reading of funerary contexts. In this work there is also the precise attempt to compensate the passivity of the vision through an emotional approach which involves the visitor on an information path in which, despite the inactivity of vision, he or she is emotionally involved.

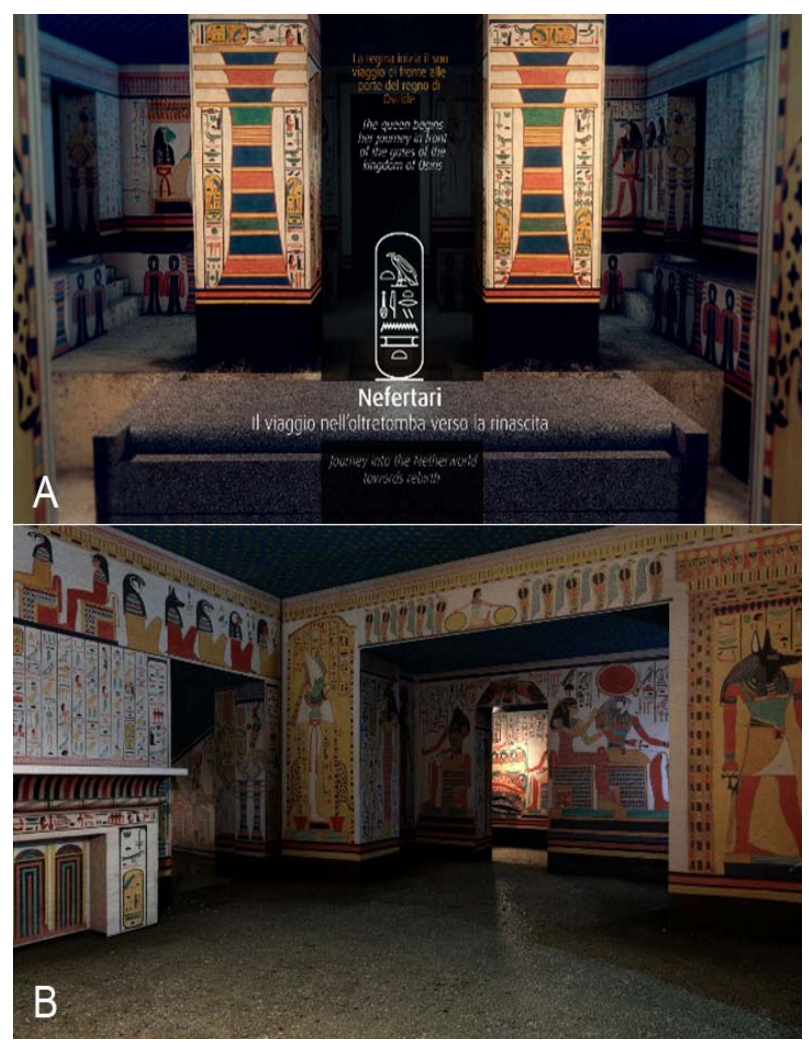

Figure 9: Reconstruction of tomb of Nefertari, starting by Schiaparelli wooden maquette: the sarcophagus hall $(A)$, the entrance hall $(B)$

\section{References}

The full video of "The tomb of Kha" is available here: https://www.youtube.com/watch?v=S7QElbjfT4w

Nefertari trailer is available here: https://www.youtube.com/watch?v=5bY-XjS5uec

CHIODI, P., 1976. Essere e tempo, Milano.

D'AMICONE, E., 2007. Nefer: la donna dell'Antico Egitto, Milano.

DONEUS, M., VERHOEVEN, G., FERA, M., BRIESE, CH., KUCERA, M. and NEUBAUER, W., 2011. From deposit to point cloud - A study of low-cost Computer Vision approaches for the straightforward documentation of archaeological excavations, in: Geoinformatics CTU FCE, pp. 81-88.

GABELLONE, F., FERRARI, I. and GIURI F., 2015. Digital restoration using Image-Based 3D models, in: Proceedings of the1st International Conference on Metrology for Archaeology Benevento- Italy, October 21-23, 2015, Benevento, pp. 478- 482.

MOISO, B., 2008. Ernesto Schiaparelli e la tomba di Kha, Torino.

NASR, M. and TOSI M., 1997. La tomba di Nefertari, Firenze.

NORBERG-SCHULZ, C., 1992. Genius Loci. Paesaggio, ambiente, architettura, Documenti di architettura, Milano.

PATIAS, P., 2007. Cultural heritage documentation, in: Fryer J., Mitchell H., Chandler J. (eds.), Application of 3D measurement from images, 59(3), pp. 225-257, Dunbeath.

POLLEFEYS, M., VERGAUWEN, M. and VAN GOOL, L., 2000. Automatic 3D modeling from image sequences, in: International Archive of Photogrammetry and Remote Sensing, Vol. XXXIII, part B5, pp. 619-626. 
REMONDINO, F. and EL-HAKIM, S., 2006. Image-based 3D modelling: a review, in: The Photogrammetric Record, 21(115), (September 2006), pp. 269-291.

VERHOEVEN, G., DONEUS, M., BRIESE, CH. and VERMEULEN, F., 2012. Mapping by matching: a computer visionbased approach to fast and accurate georeferencing of archaeological aerial photographs, in: Journal of Archaeological Science, 39, pp. 2060-2070. 